\title{
Acute Pancreatitis in the Postoperative Course after Esophagectomy: A Major Complication Described in 4 Patients
}

\author{
R.L.G.M. Blom M. van Heijl O.R.C. Busch \\ M.I. van Berge Henegouwen \\ Department of Surgery, Academic Medical Centre, Amsterdam, The Netherlands
}

\section{Key Words}

Pancreatitis · Esophagectomy · Complication

\begin{abstract}
Background: Postoperative pancreatitis is a rare but devastating complication after esophageal surgery. It has been described in connection with abdominal surgery but the etiology in connection with esophageal surgery has never been evaluated. The present study describes 4 cases of postoperative pancreatitis, and a hypothesis about the etiology is formed.
\end{abstract}

Methods: We performed a search for patients with postoperative pancreatitis after esophagectomy using our prospective database including all patients that underwent esophageal resection at our institution between 1993 and 2008. Pancreatitis was described as abdominal pain, hyperamylasemia, signs of pancreatitis on CT scan or findings during laparotomy or autopsy.

Results: A total of 950 patients underwent esophagectomy at our institution, 4 patients developed postoperative pancreatitis (incidence $0.4 \%$ ). Two out of four patients died. Discussion: Pancreatitis following esophageal surgery is a serious, potentially lethal complication. Diagnosis can be difficult as clear clinical or laboratory findings might be lacking. Peroperative manipulation of the pancreas, mobilization of the duodenum or compromized vascularization have been suggested as etiological factors; although in the described patients, none of these factors were identified as the cause of pancreatitis. In conclusion, pancreatitis following esophageal surgery is a serious but rare complication that should always be considered in patients who deteriorate postoperatively. 


\section{Introduction}

The incidence of esophageal cancer in the Western world has been rising over the past decades [1]. It is an aggressive disease with early lymphatic and hematogenous dissemination. Surgical resection with or without neoadjuvant chemoradiation gives the best chance of a long survival, but is accompanied by a high morbidity [2].

Postoperative pancreatitis is a rare complication after esophageal surgery [3]. The reported incidence of this complication is around $0.50 \%$ [4]. Pancreatitis following abdominal surgery has been investigated previously, mainly in connection with gastroduodenal surgery, with an incidence of $4-12 \%$ following biliary tract surgery and $0.8-4 \%$ after gastric surgery [5-9]. Peroperative trauma due to lymph node dissection and mobilization of the duodenum have been suggested to induce postoperative pancreatitis [7]. It is a rare but serious complication with a mortality rate varying between 17 and 50\% [10]. In the present study we evaluated the incidence and etiology of postoperative pancreatitis after esophageal surgery in our center's prospective database.

\section{Methods}

We performed a search for patients with postoperative pancreatitis using our prospective database, including all patients that underwent esophagectomy between 1993 and 2008 to identify patients with acute postoperative pancreatitis during hospital stay after esophagectomy. The database includes all patients with adenocarcinoma or squamous cell carcinoma of the esophagus, gastro-esophageal junction or the gastric cardia substantially involving the distal esophagus scheduled to undergo resection with curative intent.

\section{Surgery}

As described in previous studies performed at our institution, surgery was performed by either transhiatal or transthoracic approach [2]. In short, during transhiatal esophagectomy the esophagus was dissected under direct vision through the widened hiatus of the diaphragm up to the inferior pulmonary vein. The tumor and its adjacent lymph nodes were dissected en bloc. The paracardial, lesser-curvature, left-gastric-artery (along with the lesser-curvature), celiac-trunk, common-hepatic-artery, and splenicartery nodes were dissected and a 3-cm gastric tube was constructed. After left-sided mobilization of the cervical esophagus, the intrathoracic, normal esophagus was bluntly resected from the neck to the abdomen using a vein stripper.

Posterolateral thoracotomy was the first step in transthoracic resection with extended en bloc lymphadenectomy. The specimen included the lower and middle mediastinal, subcarinal, and rightsided paratracheal lymph nodes (dissected en bloc). Through a midline laparotomy, lymph node dissection was performed (identical to the transhiatal procedure) and a $3-\mathrm{cm}$ gastric tube was constructed. Also after a transthoracic procedure, a cervical phase was performed.

Esophagogastrostomy was performed in the neck, without cervical lymphadenectomy. The anastomosis was either made using a hand-sewn end-to-end or end-to-side technique (at surgeons' preference).

\section{Pancreatitis}

Postoperative pancreatitis was defined as upper abdominal pain and hyperamylasemia and/or characteristic signs of acute pancreatitis on CT scan. Hyperamylasemia was defined as three times the upper limit of the normal range (220 U/l). Postoperative pancreatitis could also be established during laparotomy and/or based on findings at autopsy. 


\begin{tabular}{r|l|l|l} 
Case Reports $/$ h & $\begin{array}{l}\text { Case Rep Gastroenterol 2009;3:382-388 } \\
\text { D01: 10.1159/000258092 }\end{array}$ & Published online: November 21, 2009 & $\begin{array}{l}\text { O 2009 S. Karger AG, Basel } \\
\text { ISSN 1662-0631 } \\
\text { www.karger.com/crg }\end{array}$ \\
\hline
\end{tabular}

\section{Results}

Between 1993 and 2008, a total of 950 patients underwent esophagectomy at our institution. Complications occurred in 657 patients $(69.7 \%)$ and in-hospital mortality was $3.2 \%$. Mean hospital stay was 16 days. Four out of 950 patients developed postoperative pancreatitis $(0.4 \%)$. Table 1 summarizes the outcome results of all patients who underwent esophagectomy at our institution.

\section{Patients}

A summary of all 4 cases is shown in table 2 .

\section{Case A}

Patient A, a 73-year-old man with an adenocarcinoma of the esophagus (postoperatively staged as pT3N1M0), underwent a transthoracic esophagectomy. His previous medical history showed no evidence of specific diseases. His body mass index (BMI) was 24. A splenectomy was needed for a bleeding caused by a splenic lesion. Postoperatively the patient was transferred to the intensive care unit (ICU) and developed signs of peritonitis after two days with a serum amylase level of 1,690 U/l. The critical condition of this patient required an immediate relaparotomy that showed acute pancreatitis. A drain was left in the bursa omentalis. After this procedure, the patient developed multiple organ failure but recovered in the following week. However, after another week he became septic for which ICU re-admission was needed. A bronchoscopy was performed because of air leakage during respiration. A large tracheo-esophageal fistula with bile leakage to the trachea was found via bronchoscopy. Given the condition the patient was in after several serious complications, treatment was withdrawn. The patient died 22 days after the initial esophagectomy. Autopsy confirmed the pancreatitis and showed extensive ulceration and necrosis of the gastric tube.

\section{Case B}

Patient B, a 72-year-old man with a T2N1M0 adenocarcinoma of the esophagus, underwent transthoracic esophagectomy. His medical history showed previous alcohol abuse. Preoperative CT showed no signs of pancreatitis. Postoperative recovery was complicated on day 12 by progressive respiratory insufficiency which led to re-admission to the ICU. His serum amylase level was $338 \mathrm{U} / \mathrm{l}$. The patient developed hypovolemic shock for which a relaparotomy was performed showing a focal pancreatitis with a septic bleeding of the left gastric artery stump. The bleeding was oversewn and a drain was left in the pancreatic area. Although recovery was complicated by pneumonia and pseudomembranous colitis, the patient could be discharged in a fairly good condition 55 days after the initial operation.

\section{Case C}

Patient C, a 52-year-old man with a T3N1M0 adenocarcinoma of the esophagus, underwent a transhiatal esophagectomy after neoadjuvant chemoradiotherapy. His 
medical history showed a myocardial infarction with placement of a stent. His BMI was 32.

Postoperatively the patient was transferred to the surgical ward after one day of ICU stay. Postoperative recovery was complicated by a paralytic ileus, and he became progressively dyspnoeic for which he was transferred back to the ICU six days postoperatively. The patient died on the same day after cardiac arrest due to electromechanical dissociation. Autopsy showed dilatation of the colon and extensive pancreatitis. The serum amylase level at re-admission to the ICU was $110 \mathrm{U} / \mathrm{l}$. The gastric tube was vital and the anastomosis was intact.

\section{Case D}

Patient D, a 78-year-old male with a T3N1M0 adenocarcinoma of the esophagus, underwent a transhiatal esophagectomy. His medical history showed a classical cholecystectomy in 1986 . His BMI was 26 . Postoperatively the patient's condition deteriorated for which a CT scan was performed on day 12. The CT scan showed a leakage of the proximal anastomosis of the gastric tube but no signs of pancreatitis. A relaparotomy was performed. Acute necrotizing pancreatitis and circular ischemia $1 \mathrm{~cm}$ proximal of the gastric tube were reported as well as ischemia of the greater omentum. A necrotectomy of the greater omentum was performed. After dismantling of the anastomosis, an esophagostomy was performed. A drain was left in the pancreatic area. The patient's serum amylase level on the day of the relaparotomy was $108 \mathrm{U} / \mathrm{l}$.

This patient was eventually discharged in a reasonable condition 55 days after initial surgery and was planned for reconstruction of the gastrointestinal tract.

\section{Discussion}

In the present series of approximately 1,000 patients, the incidence of postoperative pancreatitis was only $0.4 \%$ (4 patients). However, it might well be possible that this complication is under-reported since the diagnosis can rather easily be missed.

The incidence of the present series is highly comparable to the incidence as reported in the literature of around 0.50 [4]. Therefore, it is not likely that postoperative pancreatitis has been missed in many patients.

Pancreatitis can be diagnosed based on a combination of upper abdominal pain, laboratory findings and abnormal findings on CT [10]. Laboratory findings that may accompany pancreatitis include hyperamylasemia and/or hyperlipasemia. Frequently observed clinical manifestations of acute pancreatitis include one or more of the following symptoms: abdominal pain, fever, nausea, vomiting and decreased bowel sounds. These features seem, however, not specific to acute pancreatitis. The positive-predictive value of clinical signs and symptoms for diagnosing acute pancreatitis has not been investigated before. The positive-predictive value of hyperamylasemia and hyperlipasemia for diagnosing acute pancreatitis is $15-72$ and $90 \%$, respectively [11]. In the present series, one out of four patients presented with an elevated serum amylase besides signs of peritonitis. The other patients showed no signs of acute pancreatitis, which emphasizes the possibility of under-reporting. 
Pancreatitis following abdominal surgery has been described previously in connection with gastroduodenal surgery such as gastric resections and biliary tract surgery [5-9]. The mortality rate varies between 17 and 50\% [8]. Peroperative trauma to the pancreas and mobilization of the duodenum have been suggested to induce postoperative pancreatitis [7]. Other causes that have been reported are compromised vascularization in the pancreatic area, either by ischemic injury due to hypovolemic shock or by a thromboembolism, or obstruction of the pancreatic duct $[5,6,8]$. During esophagectomy central celiac lymphadenectomy is performed, and compression is applied to the peripancreatic area. This compression might cause irritation and obstruction of the pancreatic duct which may result in acute pancreatitis.

During relaparotomy, patient A showed a bleeding in the splenic area, which may have induced acute pancreatitis due to ischemia of the pancreatic tissue. It could also be possible this patient already had a pancreatitis before the splenectomy was performed. Patient B developed hypovolemic shock 12 days postoperatively which makes it unlikely that this bleeding was caused peroperatively and led to pancreatitis. It is more likely that the pancreatitis in this patient was the cause of a septic bleeding.

In case of surgery not involving the pancreatic area, pancreatitis is suggested to develop as a result of general inflammation, shock, hypoxia or peritonitis [7]. Patient A was diagnosed with peritonitis two days postoperatively and patient B was diagnosed with hypovolemic shock 12 days after surgery, which in these cases could have been the causes of pancreatitis.

Over 85 drugs have been reported to cause acute pancreatitis varying from a definite to a possible association [12]. Most of these associations are not evidence-based. Different mechanisms of drug-induced pancreatitis have been proposed. It has been suggested to be caused either by hypersensitivity of the pancreas or due to accumulation of a toxic metabolite [12]. Patient C and D both used medication that has been reported to be a possible cause of pancreatitis (lansoprazol and lisinopril, respectively) [13]. Both patients, however, already used the drugs on a regular basis before they were admitted to the hospital. It is therefore unlikely that the use of the drugs caused the postoperative pancreatitis in these patients.

A review of the medical history of these four patients only reveals alcohol abuse in patient $\mathrm{B}$, which may have increased his chance of developing pancreatitis [12, 14, 15].

In these four cases it was not possible to indicate a definitive cause of postoperative pancreatitis. Two out of four patients died due to postoperative complications including pancreatitis, and only one of the two surviving patients still had an intact anastomosis at discharge. The only similar aspect in all four cases was the severe and rapid postoperative deterioration.

In conclusion, pancreatitis following esophageal surgery is a serious but rare complication with an incidence of $0.4 \%$. It can lead to hypovolemia and multiple organ failure which increases the possibility of anastomotic leakage. Due to lack of hyperamylasemia, diagnosis is easily missed and under-diagnosis is likely.

Pancreatitis remains difficult to diagnose in patients who underwent esophageal surgery due to occurrence of various other, more frequent complications with similar symptoms. It is, however, important to recognize postoperative pancreatitis at an early phase, and it should always be considered in patients who unexpectedly deteriorate rapidly in the postoperative phase. 
Table 1. Results of 950 patients who underwent esophageal surgery between January 1993 and December 2008

\begin{tabular}{lc}
\hline Outcome parameters & Number of patients \\
\hline In-hospital mortality & $30(3.2 \%)$ \\
Minor complications & $496(52.7 \%)$ \\
Major complications & $161(17.1 \%)$ \\
Postoperative pancreatitis & $4(0.4 \%)$ \\
Mean hospital stay, days (range) & $16(3-211)$ \\
\hline
\end{tabular}

Minor complications: atelectasis, recurrent laryngeal nerve injury, pneumonia, chyle leakage, pulmonary embolus, anastomotic leakage. Major complications: heart failure, ischemic stroke, renal insufficiency, sepsis.

Table 2. Summary of the 4 cases

\begin{tabular}{|c|c|c|c|c|}
\hline & Patient A & Patient B & Patient C & Patient D \\
\hline Age & 73 & 72 & 52 & 78 \\
\hline Medical history & - & alcohol abuse & $\begin{array}{l}\text { myocardial } \\
\text { infarction }\end{array}$ & $\begin{array}{l}\text { classical } \\
\text { cholecystectomy }\end{array}$ \\
\hline BMI & 24 & 25 & 32 & 26 \\
\hline Type of procedure & TTE & TTE & THE & THE \\
\hline $\begin{array}{l}\text { Type and stage of } \\
\text { carcinoma }\end{array}$ & $\begin{array}{l}\text { adenocarcinoma } \\
\text { T3N1M0 }\end{array}$ & $\begin{array}{l}\text { adenocarcinoma } \\
\text { T2N1M0 }\end{array}$ & $\begin{array}{l}\text { adenocarcinoma } \\
\text { T3N1M0 }\end{array}$ & $\begin{array}{l}\text { adenocarcinoma } \\
\text { T3N1M0 }\end{array}$ \\
\hline $\begin{array}{l}\text { Postoperative } \\
\text { presentation of } \\
\text { pancreatitis }\end{array}$ & $\begin{array}{l}\text { peritonitis } \\
2 \text { days } \\
\text { postoperatively }\end{array}$ & $\begin{array}{l}\text { hypovolemic shock } \\
12 \text { days } \\
\text { postoperatively }\end{array}$ & $\begin{array}{l}\text { paralytic ileus } \\
6 \text { days } \\
\text { postoperatively }\end{array}$ & $\begin{array}{l}\text { anastomotic } \\
\text { leakage } \\
12 \text { days } \\
\text { postoperatively }\end{array}$ \\
\hline $\begin{array}{l}\text { Amylase level on the } \\
\text { day of diagnosis, U/l }\end{array}$ & 1,690 & 338 & 110 & 108 \\
\hline Diagnosis based on & relaparotomy & relaparotomy & autopsy & relaparotomy \\
\hline $\begin{array}{l}\text { Other findings on } \\
\text { diagnosis }\end{array}$ & - & $\begin{array}{l}\text { septic bleeding of } \\
\text { the gastric artery } \\
\text { stump }\end{array}$ & $\begin{array}{l}\text { dilatation of the } \\
\text { colon }\end{array}$ & $\begin{array}{l}\text { ischemia of the } \\
\text { proximal gastric } \\
\text { tube/omentum }\end{array}$ \\
\hline $\begin{array}{l}\text { Treatment of the } \\
\text { pancreatitis }\end{array}$ & $\begin{array}{l}\text { drainage } \\
\text { procedure }\end{array}$ & $\begin{array}{l}\text { drainage } \\
\text { procedure }\end{array}$ & - & $\begin{array}{l}\text { drainage } \\
\text { procedure }\end{array}$ \\
\hline Postoperative course & $\begin{array}{l}\text { died } 22 \text { days } \\
\text { postoperatively }\end{array}$ & $\begin{array}{l}\text { discharged } 55 \text { days } \\
\text { postoperatively }\end{array}$ & $\begin{array}{l}\text { died } 6 \text { days } \\
\text { postoperatively }\end{array}$ & $\begin{array}{l}\text { discharged } 55 \text { days } \\
\text { postoperatively }\end{array}$ \\
\hline Cause of death & $\begin{array}{l}\text { multiple organ } \\
\text { failure }\end{array}$ & - & $\begin{array}{l}\text { electromechanical } \\
\text { dissociation }\end{array}$ & - \\
\hline
\end{tabular}

$\mathrm{BMI}=$ Body mass index; TTE $=$ transthoracic esophagectomy THE $=$ transhiatal esophagectomy 


\section{References}

1 Parkin DM, Bray FI, Devesa SS: Cancer burden in the year 2000. The global picture. Eur J Cancer 2001;37(suppl 8):S4-S66.

- Hulscher JB, van Sandick JW, de Boer AG, Wijnhoven BP, Tijssen JG, Fockens P, et al: Extended transthoracic resection compared with limited transhiatal resection for adenocarcinoma of the esophagus. N Engl J Med 2002;347:16621669.

3 Mulholland MW, Doherty GM: Complications in Surgery. Philadelphia, Lippincott Williams \& Wilkins, 2005.

$\checkmark 4$ Gockel I, Exner C, Junginger T: Morbidity and mortality after esophagectomy for esophageal carcinoma: a risk analysis. World J Surg Oncol 2005;3:37.

5 Burkey SH, Valentine RJ, Jackson MR, Modrall JG, Clagett GP: Acute pancreatitis after abdominal vascular surgery. J Am Coll Surg 2000;191:373-380.

-6 Griffith JP, Eu KW, Leong AWR, Ho YH, Nyam D, Seow-Choen F: The significance of hyperamylasaemia after colonic resection. Colorectal Dis 1999;1:347-350.

7 Ponka JL, Landrum SE, Chaikof L: Acute pancreatitis in the postoperative patient. Arch Surg 1961;83:475-490.

8 Thompson JS, Bragg LE, Hodgson PE, Rikkers LF: Postoperative pancreatitis. Surg Gynecol Obstet 1988;167:377-380.

-9 White MT, Morgan A, Hopton D: Postoperative pancreatitis. A study of seventy cases. Am J Surg 1970;120:132-137.

10 Ranson JH: Diagnostic standards for acute pancreatitis. World J Surg 1997;21:136-142.

11 Koizumi M, Takada T, Kawarada Y, Hirata K, Mayumi T, Yoshida M, et al: JPN Guidelines for the management of acute pancreatitis: diagnostic criteria for acute pancreatitis. J Hepatobiliary Pancreat Surg 2006;13:25-32.

12 Steinberg W, Tenner S: Acute pancreatitis. N Engl J Med 1994;330:1198-1210.

13 www.fk.cvz.nl. 2008. Ref Type: Internet communication.

14 Fernández-del Castillo C, Rattner DW, Warshaw AL: Acute pancreatitis. Lancet 1993;342:475-479.

15 Kloppel G, Maillet B: Pathology of acute and chronic pancreatitis. Pancreas 1993;8:659-670. 